\title{
REFLEXÕES SOBRE A PROCRIAÇÃO ARTIFICIAL E OS DIREITOS DAS CRIANÇAS
}

\section{Paulo Antonio de Carvalho Fortes ${ }^{1}$}

FORTES. P. A. C. Reflexões sabre a Procriação Artificial e os Direitos da Criança. Rev. Bras. Cresc. Des. Hum., São Paulo, 111(2), 1993.

Resumo: O autor levanta algumas indagações de caráter ético e jurídico sobre as repercussões dos direitos das crianças em razão da utilização do processo de procriação artificial. Cromenta normatizaçõs e decisões judiciais estrangeiras referentes à matéria.

Palavras-chave: responsabilidade, direito, ética, pratica medica

Summary: The author raises a few inquires concerning the juridical and ethical feature about the efects on children's rights, cause of process application of new reproductive technology. He also conments rules, principal and foreign judicial decisions about the matter.

Key words: responsability, rights, ethics, medical pratice.

\section{CIÊNCIA MODERNA E OS DIREITOS HUMANOS}

A cvolução tccnológica c científica que vem ocorrendo nas últimas décadas, trouxe um grande poder ao homem para atuar sobre as condições físicas e psíquicas do próprio ser humano. A realização dos transplantcs de órgãos e de tecidos, a viabilidade do reconhecimento antenatal das condições dc viabilidade do feto, as atividades da engenharia gcenética como a manipulação de gametas, a possibilidade da escolha do sexo da criança a ser geslada, a inseminação artificial, a fertilização "in vitro", enlre outras, são inovações técno-cicntíficas que trazem a imperiosa neccssidade de profunda relação filosófica, ética e jurídica sobre as repercussõcs dessas práticas nos direitos fundamentais que devenm reger a vida humana.

As conquistas científicas devem visar o bem do ser humano e porisso há necessidade que seus resultados e consequências sejam limitados pela manutenção das garantias e liberdades dos indivíduos, preservando-se a dignidade do ser humano, seu direito à vida, à saúde e à integridade física e psíquica. O interesse de cada indivíduo deve prevalecer sobre o da sociedade e o da ciência, como disposto na Declaração de Helsinki, de 1964, elaborada pela Associação Médica Mundial, a respeito da realização de pesquisas sobre o ser humano .

A dignidade da pessoa humana é principio inserido na Nonma Constitucional Brasileira (art. $\left.\mathrm{I}^{\wedge} \mathrm{Q}, \mathrm{III}\right)$ e qualquer atividade científica deve ser

1 Professor Faculdade de Saúde Pública da USP - Centro de Estudos e Pesquisas de Direito Sanitário. Av. Dr. Arnaldo, 715 subsolo - São Paulo - SP - CEP 01246-001 - Tel.: 280-3233 r. 267. 
balizada por tal dirctriz, assim como objetivada pela promoção do bem comum (art. 3-, IV).

O homem além de seu caráter individual, tem uma dimensão social traduzida no reflcxo de sua vida, suas atitudes, seus conceitos, seus julgamentos, sua reputação nos contextos sociais onde está inserido. Sendo assim, o indivíduo deve ter assegurado o poder da livre manifestação de sua vontade sobre tudo o que disser respeito a seu corpo, expressando-a através do consentimento. Consentimento este livre de coações físicas e psíquicas, de erros, enganos ou atos dolosos. Esclarecido por meio de infonnaçõcs que norteiem suas decisões sobre aspectos biológicos, jurídicos, éticos e econômicos.

Cabe dizer que o consentimento só é válido para atos lícitos, não exonerando práticas culposas ou dolosas que infrinjam os limites estabelecidos pela lci.

Princípio este a ser também resguardado nas reflcxõcs sobre as medidas científicas modernas c na sua relação com os direitos humanos, é o que coloca o corpo humano como fora das relações comerciais, insusectivel de apropriação e de alienação. Tal princpípio é reforçado pelo disposto no art. $199, \S 4^{\circ}$ da Constituição Federal, referente a remoção de tecidos, substâncias e órgãos humanos para pesquisas, transplantes e tratamentos, vedando qualquer forma de comercialização.

\section{DIREITO À REPRODUÇÃO}

O poder de intervenção do homem sobre o processo biológico, que vinha até agora sendo controlado por via natural, Ieva ao manifesto desejo dos indivíduos em aceder a essa nova forma de liberdade como também da própria sociedade em utilizá-la em seu proveito. A atual Carta Constitucional refere-se ao direito do cidadão brasileiro ao planejamento familiar (art. 226, $\S 7^{\circ}$ ), tanto para evitar a geração de crianças, quanto para procria-las, direito baseado na livre decisão do casal e cabendo ao Estado proporcionar recurso de informação e de educação para garantir a eficácia do principio.

Resta saber se devem ser estabelecidas normas legais que fixem os limites de intervenção da sociedade no domínio da reprodução humana artificial por intermédio de regulamentação infraconstitucional, ou se é preferível deixar o assunto na dependência da vontade do casal da consciência ética dos profissionais de saúde e das decisões deontológicas e jurisprudências, quando da resolução de problemas concretos advindos da realidade dos fatos. CALLAHAN nos lembra que ainda não há um consenso na sociedade sobre o comportamento ético da tecnologia existente para planejar, limitar ou interromper as gravidezes; ainda não há o preparo adequado para avaliar-se eticamente as mais novas alternativas de reprodução artificial. ${ }^{2}$

A inexistência de regras específicas faz com que o estudo e, discussão sobre esta temática seja baseada nos princípios gerais da ética e do direito brasileiro e nas experiências provenientes dos países onde as técnicas de reprodução artificial estão mais desenvolvidas e já vêm suscitando, há algum tempo, interrogações legais éticas.

\section{A PROCRIAÇÃO ARTIFICIAL}

Consiste na inseminação cirúrgica de uma mulher com o esperma de seu marido, companheiro ou terceiro, ou a fecundação “in vitro" graças aos gametas do casal ou de terceiros.

A procriação artificial se utiliza de dois métodos básicos. A técnica de inseminação artificial de gametas masculinos diretaunente no útero feminino e a fertilização realizada “in vitro", onde há o encontro dos gametas masculinos com o óvulo feminino em condições laboratoriais dando origem a um embrião, que por técnicas de congelamento e descongelamento, são conservados para serem posteriormente implantados no útero da doadora do óvulo ou de outra mulher.

A inseminação pode ser homóloga, quando são utilizados os gametas do próprio casal ou heteróloga, quando o embrião resultar de gametas provenientes de terceiros, estranhos ao casal.

Há, portanto, três situações possíveis para a procriação artificial:

I - intervenção no seio do próprio casal; gametas;

II - intervenção com terceiro doador de

III- intervenção com a participação de terceiro procriados, denominado de mãe substituia ou popularmente conhecida como "barriga de aluguel”.

Atualmente, no Brasil, estima-se que as técnicas utilizadas levem a um resultado desejável, ou seja, o nascimento de uma criança normal, em torno de 10 a $25 \%$ das vezes ${ }^{4}$.

\section{A PROCRIAÇÃO ARTIFICIAL E OS DIREITOS DAS CRIANÇAS}

Há um direito irrestrito à procriação artificial? Todas as pessoas têm, em quaisquer condições, direito a ter uma criança gerada artificialmente, sob a alegação do princípio da autonomia e da liberdade individual? 
Um casal com graves distúrbios mentais pode requerer a utilização de técnicas de reprodução artificial? Será permitido que mulher solteira ou viúva possa praticar procedimentos que resultem em uma gravidez artificial? É ético e legal a inseminação artificial de gametas masculinos ou de embrião derivado de progenitor já falecido?

Quando prevalece o direito dos pais em situação de confronto com os direitos das crianças? É direito da criança ter uma família ao nascer, constituída de pai e mãe, ou basta somente a presença materna? A criança deve ser encarada como um fim em si mesma ou um meio para a realização de interesses ou desejos dos adultos?

No final de 1992, o Conselho Federal de Medicina estabeleceu algumas regras para a utilização da "reprodução assistida", através da resolução $n^{\circ}$ 1358/92, trazendo resposta a algumas das indagações feitas. Permite, esta resolução, que toda mulher legalmente capaz possa ser receptora das técnicas de reprodução assistida, quando de sua concordância .

As atuais proposições legislativas francesas, por exemplo, vedam a reprodução artificial para mulheres solteiras e viúvas, argumcntando que deve prevalecer o interesse da criança sobre a satisfação dos pais ou da mulher em trazer alguém a este mundo e que essa tem o direito de nascer no seio de uma família constituida ${ }^{9}$.

Recentemente a Suprema Corte americana rejeitou o recurso impetrado por uma senhora que ensejava utilizar os óvulos fertilizados pelo sêmen congelado de seu ex-marido, contra a vontade deste ${ }^{6}$.

Será esse o entendimento que tem a sociedade brasileira neste momento histórico?

As técnicas de procriação artificial foram desenvolvidas como meios de luta contra a esterilidade masculina, feminina ou de ambos os membros do casal. Sendo assim, podem ser utilizadas como uma nova forma de procriação, vindo substituir a proeriação natural, sendo realizada sem razões médicas, simplesmente para conforto do casal ou da mulher?

Um casal que é capaz de procriar normalmente está legitimado a demandar a realização de procedimentos de procriação artificial?

Antes da realização dos procedimentos técnicos, o profissional de saúde deve constatar devidamente a existência de esterilidade irreversível ou a presença de condições de forte transmissão de afecções consideradas como incuráveis pelos conhecimentos científicos do momento?

Fundamental é que os procedimentos devam ser realizados por profissionais médicos devidamente habilitados e em instituições que con- greguem recursos humanos, técnicos e materiais condizentes com as necessidades científicas para tais práticas.

Indaga-se, ainda, se é papel do Poder Público normalizar sobre quais parâmetros e variáveis devam ser consideradas na escolha dos doadores.

Consideramos que a doação deve manter o princípio da gratuidade, ser uma ação altruística, um gesto humanitário e não uma transação comercial, pois o corpo humano está fora das relações comerciais. Sabe-se da dificuldade. de se manter este princípio na prática diária das atividades de pesquisa e de assistência reprodutiva, mas consideramos que para sua preservação fazse necessário que ocorram campanhas de esclarecimento e conscientização sobre os benefícios do gesto da doação com essa finalidade.

E da essência do processo que se mantenha o anonimato do doador. Correntes doutrinárias advogam o anonimato absoluto, vedando o conhecimento da identidade do doador dos gametas em todas as condições, e argumentam que, assim, a criança poderá crescer e desfrutar de sua filiação suposta de maneira plena. ${ }^{10}$

Nesse caso a lei deve estabelecer que não exista relação alguma entre o doador e a criança nascitura devendo, os vínculos desta, ser apenas com os pais naturais.

Há outras correntes que defendem o anonimato relativo, podendo este ser rompido em condições especiais mediante autorização judicial. Lei sueca, de 1980, permite à criança que atingiu sua maioridade, ser informada de sua filiação biológica. FERRAZ esposa a mesma tese, considerando que o sigilo relativo ao doador poderá ser rompido quando for de interesse da criança obter informações genéticas extremamente necessárias para sua vida ou sua saúde. ${ }^{5}$

Quanto ao doador, este não deve ter o poder de influenciar na escolha dos receptores de suas células germinais e nem ter o conhecimento da identidade dos donatários ${ }^{9}$.

O consentimento à prática de procriação artificial é atribuido aos membros do casal, seja qual for sua condição marital, devendo ser expresso. No caso de doação de gametas deve-se obter o consentimento do doador para a utilização do seu património genético. Quando casados ou em união estável, será necessário o consentimento do cônjuge ou companheiro, sob pena de ser alegada violação grave ao dever conjugal de exclusividade de procriação no seio do casal.

Questão altamente controversa refere-se à intervenção de terceiro procriador - a maternidade de substituição. Paises como a Alemanha, a França e a Austrália impedem essa prática, que é 
permitida por diversos estados americanos. A igreja Católica, de grande influência cultural em nosso pais, através do Direito Canônico, se coloca em posição frontalmente contrária a esse tipo de procriação. ${ }^{7}$

O Comitê permanente para o estudo dos aspectos éticos da reprodução humana da Federação internacional de Ginecologistas-Obstetras, em 1989, pelo entendimento da maioria de seus membros, considerou que a maternidade de substituição pode ser admitida como uma prática válida em situações muito particulares e raras, mas todo o processo deve ter a aprovação de um Comitê de Ética e manter-se sob estrito controle médico. Alertam para que sejam evitadas situações de exploração das mulheres que, em virtude de suas precárias situações sociais aceitem serem mães substitutas utilizando seu corpo como fonte financeira. ${ }^{10}$

A Resolução do Conselho Federal de Medicina estabelece validade ética para o procedimento em caso de problema médico que impeça ou contra-indique a gestação na doadora genética. A mãe substituta deverá ser da familia da doadora genética, num parentesco de até segundo grau, cabendo aos Conselhos

\section{REFERÊNCIAS BIB1.IOGRÁFICAS}

1. BELANGER, M. Droit international de la santé por les textes. Paris, Berger-levrault, 1989. p. 304-5.

2. CALL ALLAN, S. The ethical challenge of the new reproduct; ve technology. In MONAGLE, J. E; THOMASMA, D.C. ed. Medical Ethics. Rockville, Aspeú Publishers Inc., 1988. p. 2637.

3. CONSELHO FEDERAL DE MEDICINA. Resolução n ${ }^{\circ}$ 1358/92, de 11.11.92.

4. CONSELHO REGIONAL DE MEDICINA DO ESTADO DE SÃO PAI 1LO. Reprodução assistida: amplo debate. JornaI do CREMESP, 48: 6-7, 1989.

5. FERRAZ, S. Manipulações biológicas e princípios constitucionais: uma introdução. Porto Alegre, Sergio Antonio Fabris Editor, 1991.
Médicos Regionais a autorização para outras situações. ${ }^{3}$

A utilização dessa técnica traz o questionamento de saber quem é a mãe verdadeira da criança nascida? A mãe biológica, produtora do óvulo ou aquela responsável pela gestação e pelo parto, a mãe natural?

Quem deve ficar com a criança em caso de discordância juridica em casos concretos? A Iegislação francesa optou por considerar que é a mãe natural a responsável pela criança. Por sua vez, a jurisprudência americana conduziu a uma solução oposta, pois toma em conta o contrato estabelecido entre os genitores biológicos e a "mãe de aluguel”. Acatando o principio da responsabilidade contratual, detemina que a criança permanece com os pais biológicos.

Por fim, vale ressaltar que na ausência de regras éticas e jurídicas já definidas e com a ampliação das possibilidades em nosso país para a realização das técnicas de procriação artificial, é imperioso que a sociedade, juntamente com os profissionais de saúde prcocupados com a questão ética, como os juristas, ampliem a discussão e a reflexão sobre o tema e suas consequências sociais sobre os direitos das crianças.

6. FOLI IA DE SÃO PAULO. Justiça impede mulher de usar os óvulos fertlizados pelo ex-marido, 23 de Fevereiro de 1993.

7, PESSINI, L.; BARCHIFONTAINE, C. de P. Problemas atuais de bioética. São Paulo, Edições Loyola, 1991. p. 143-164.

8. REVILLARD, M.; REVILLARD, J. P. Aspects éthiques et juridiques liés à la maitrisse de la production. Journal de Medicine Légale, 26 (3) 215-240, 1983

9. SUBEAU C. De l'éthique au droit. Du droit à la pratique. Concours Medical, 110 (3): 39773982, 1988.

10. Aspects éthiques de la réproduction humaine. Concours medical, 111 (1): 43-45, 1989. 